\title{
Surface integrity in wire-EDM tangential turning of in situ hybrid metal matrix composite $\mathrm{A} 359 / \mathrm{B}_{4} \mathrm{C} / \mathrm{Al}_{2} \mathrm{O}_{3}$
}

https://doi.org/10.1515/secm-2017-0391

Received November 27, 2017; accepted April 24, 2018; previously published online August 3, 2018

Abstract: In this work, wire electric discharge turning, a novel and unconventional technique, was used for the turning operation of a newly developed hybrid metal matrix composite of aluminum $\left(\mathrm{A} 359 / \mathrm{B}_{4} \mathrm{C} / \mathrm{Al}_{2} \mathrm{O}_{3}\right)$ fabricated inhouse by electromagnetic stir casting. The objective of the work was to examine the effect of rotational speed on the elements of surface integrity. It involved the measurement of various parameters such as the roughness $(R a, R q, R z)$, morphology of the recast layers, microhardness variation, and the formation of residual stresses on the machined surface and in the subsurface during the operation. The quality of the turned surface was examined by 3D surface visualization images and surface topographical details obtained by an Olympus LEXT OLS 3100 laser confocal microscope. Further, surface study at the microscopic level was done by field-effect scanning electron microscopy (FE-SEM) images to examine the surface defects. The measurement results revealed a successful turning operation, which showed a dull, textured surface without any specific texture or pattern on the machined surface. The surface had many peaks and valleys with small-scale of defects such as surface porosity. However, these defects were negligible and resulted in a smooth surface finish at high rotational speeds.

*Corresponding author: Ashish Kumar Srivastava, Mechanical Engineering, G. L. Bajaj Institute of Technology and Management, Greater Noida, G.B. Nagar (UP), India; and Mechanical Engineering, Indian Institute of Technology (ISM), Dhanbad, Jharkhand, India, e-mail: ashish7185@gmail.com

Akash Nag and Amit Rai Dixit: Mechanical Engineering, Indian Institute of Technology (ISM), Dhanbad, Jharkhand, India

Sergej Hloch: Material Disintegration, Institute of Geonics of the CAS, Ostrava-Poruba, Czech Republic; and Mechanical Engineering, Faculty of Manufacturing Technologies - TUKE, Tuke, Slovak Republic

Sandeep Tiwari: Mechanical Engineering, Krishna Engineering College, Ghaziabad, India

Jiri Scucka: Department of Laboratory Research on Geomaterials, Institute of Geonics of the CAS, Ostrava-Poruba, Czech Republic Praveen Pachauri: Mechanical Engineering, Noida Institute of Engineering and Technology, G.B. Nagar, India

O Open Access. (c) BY (c) 2019 Walter de Gruyter GmbH, Berlin/Boston
Keywords: hybrid MMC; microhardness; residual stresses; surface integrity; wire electric discharge turning.

\section{Abbreviations}

MMC metal matrix composite

HMMC hybrid metal matrix composite

WEDM wire electric discharge machining

WEDT wire electric discharge turning

\section{Symbols}

$\begin{array}{ll}d & \text { Diameter }(\mathrm{mm}) \\ R a, R q, R z & \text { Surface roughness profile parameter }(\mu \mathrm{m}) \\ \text { MRR } & \text { Material removal rate }\left(\mathrm{mm}^{3} / \mathrm{min}\right)\end{array}$

\section{Introduction}

Metal matrix composites (MMCs) are advanced materials containing the nonmetallic phase of the reinforcing material in the metallic phase of the matrix alloy and having improved properties compared to those of the basic alloy. Aluminum composites are very suitable materials for the automobile and aircraft industries because of their favorable properties such as light weight, high hardness, higher tensile and compressive strengths, better wear, and high corrosive resistance [1-3]. Reinforcements are added to the base alloy depending on the final desired properties [4]. The addition of two or more reinforcements into the metal matrix makes hybrid MMCs, which can overcome the negative aspects of the MMC with a single reinforcement $[5,6]$. MMCs are used in manufacturing industries because of their extensive applcations. However, machining of these materials is still a challenging task. The presence of hard reinforcing particles in the MMCs leads to the high tool wear. Moreover, carbide tools show significant tool wear even for a very short period of machining [7]. 
Unconventional machining provides better alternatives for machining these materials compared to conventional machining $[7,8]$. Thermal erosion processes, such as wire electric discharge machining (WEDM) [8], and cold alternative methods such as abrasive waterjet machining $[4,5]$ are the preferred methods in this regard. WEDM is a thermal erosion process through spark generation by using a wire electrode against an electrically conductive work material [9]. The electric discharge produced during the operation erodes the material from the workpiece by initiating small cracks and craters via melting and vaporizing the material, which is then flushed away by means of a dielectric fluid. The process is suitable for generating intricate 2D and 3D shapes with good accuracy and high surface finish. It is suitable for hard-to-cut materials such as steels, alloys, and composites [10]. The process is capable of making dies and engine parts more efficiently than conventional machining which involves many processes such as cutting, grinding, and polishing and leads to higher cycle time [11]. WEDM can also be used for turning operations, known as wire electric discharge turning (WEDT), which is an alternative to abrasive waterjet turning [12]. In WEDT, a cylindrical workpiece rotates axially against the traverse motion of the wire electrode (Figure 1), which helps the removal of the material from the surface of the workpiece.
The major process parameters of WEDM and WEDT are similar; however, in WEDT the rotational speed (in rpm) is also considered, which affects the process outcome [12]. The surface integrity of the turned surface plays a major role in assessing the quality of the machined surface and its subsurface. The characteristics of the subsurface include the thickness of the heat-affected zone (HAZ), which depends on various process parameters [13]. A surface free from defects (such as tearing, cracks, phase transformation, plastic deformation, and recrystallization) and has better roughness value, high fatigue life, and high dimensional accuracy is in great demand in today's manufacturing industries. The WEDM process is greatly affected by the melting and vaporization of the machined surface and its subsurface, which depend on the machining parameters such as the discharge current. At high discharge currents, the material undergoes a higher level of melting and vaporization due to the heat generated, which tends to case-harden the machined surface and in some cases extend to a depth beneath the surface [13, 14]. These surface studies are also necessary because of the occurrence of microstructural changes, hardening of the layers, and phase transformation. It also causes variations in the microhardness values. The measurement of microhardness during the machining of MMCs plays an important role in deciding the surface quality. In the case

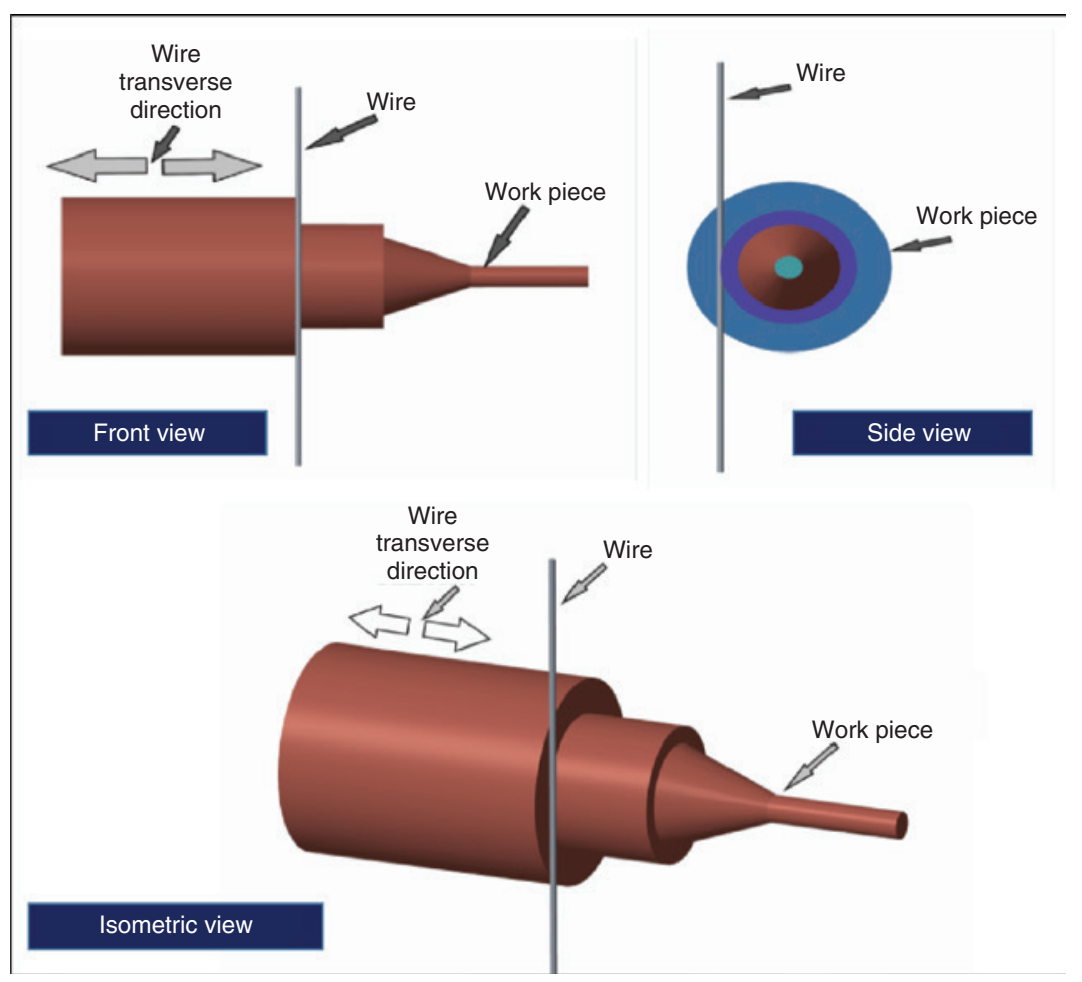

Figure 1: Cutting mechanism in WED turning. 
of MMCs, the microhardness of the machined surfaces is characterized by the fine-grained structure and homogeneous mixing of thee reinforcements $[15,16]$. The rapid cooling during WEDT increases uneven solidification. It also leads to an increase in porosity and micro-holes in the recast layer, due to which the sudden changes of microhardness on the machined surface and in the depth below the machined surfaces can result.

A significant amount of work has been done on the integrity of the surface machined by WEDM for flat surfaces, but limited work exists on the WEDT of cylindrical surfaces. Masuzawa et al. [17], for the first time, reported the turning operation via WEDM to manufacture smalldiameter pins and a shaft, which were used as a part of a tool for micro-EDM application. They found that the wire speed, power, and servo voltage were significant parameters for obtaining roundness. However, surface roughness was greatly affected by the power. Haddad et al. [18] investigated the effect of the machining parameters on the

Table 1: Thermophysical properties of $\mathrm{A} 359$ alloy, $\mathrm{Al}_{2} \mathrm{O}_{3}$, and $\mathrm{B}_{4} \mathrm{C}$.

\begin{tabular}{lrrrr}
\hline & $\begin{array}{r}\text { Density } \\
\left(\mathrm{g} / \mathrm{cm}^{3}\right)\end{array}$ & $\begin{array}{r}\text { Thermal } \\
\text { conductivity } \\
(\mathbf{W} / \mathbf{m ~ K})\end{array}$ & $\begin{array}{r}\text { Specific gravity } \\
\left(\mathrm{g} / \mathrm{cm}^{3}\right)\end{array}$ & $\begin{array}{r}\text { Melting point } \\
\left({ }^{\circ} \mathrm{C}\right)\end{array}$ \\
\hline $\mathrm{A}_{359}$ & 2.66 & 152 & 2.68 & 600 \\
$\mathrm{Al}_{2} \mathrm{O}_{3}$ & 3.2 & 100 & 3.7 & 2072 \\
$\mathrm{~B}_{4} \mathrm{C}$ & 2.52 & $30-42$ & 2.51 & 2445 \\
\hline
\end{tabular}

surface roughness, roundness, and material removal rate (MRR) in the cylindrical WEDT of AISI D3 tool steel. They examined the integrity of the machined surface and subsurface. Scanning electron microscopy (SEM) images were presented to explain surface defects such as craters and macro-ridges. They also discussed the depth of the HAZ to explain the subsurface properties. In continuation of their study, Haddad and Tehrani [19] reinvestigated the effect of the machining parameters on MRR in cylindrical WEDT by using the response surface methodology (RSM). It was observed that for maximum MRR, the voltage and power should be fixed at the highest values and other parameters should be set at minimum. Mohammadi et al. [20] worked on the optimization of MRR using statistical analysis in WEDT. The effect of multiple parameters, such as power, voltage, time-off, wire speed, wire tension, rotational speed, and servo voltage, on MRR was investigated. Signal-to-noise $(\mathrm{S} / \mathrm{N})$ ratio analysis was used to obtain the optimal condition. Rajkumar et al. [21] studied the turning of the Al/SiCp MMC by WEDT. A regression equation was derived for MRR for easier prediction. The results showed that high pulse on-time, medium gap voltage, and lower spindle speed led to higher MRR and efficient machining. Jabbaripour et al. [22] studied the microhardness of the recast layer deposited during EDM machining of Ti6Al4V. The results showed that an increase in pulse energy increased the microhardness and thickness of the recast layer deposited. Baki et al. [23] machined the Ti-6Al-4V titanium alloy by WEDT to optimize the input parameters

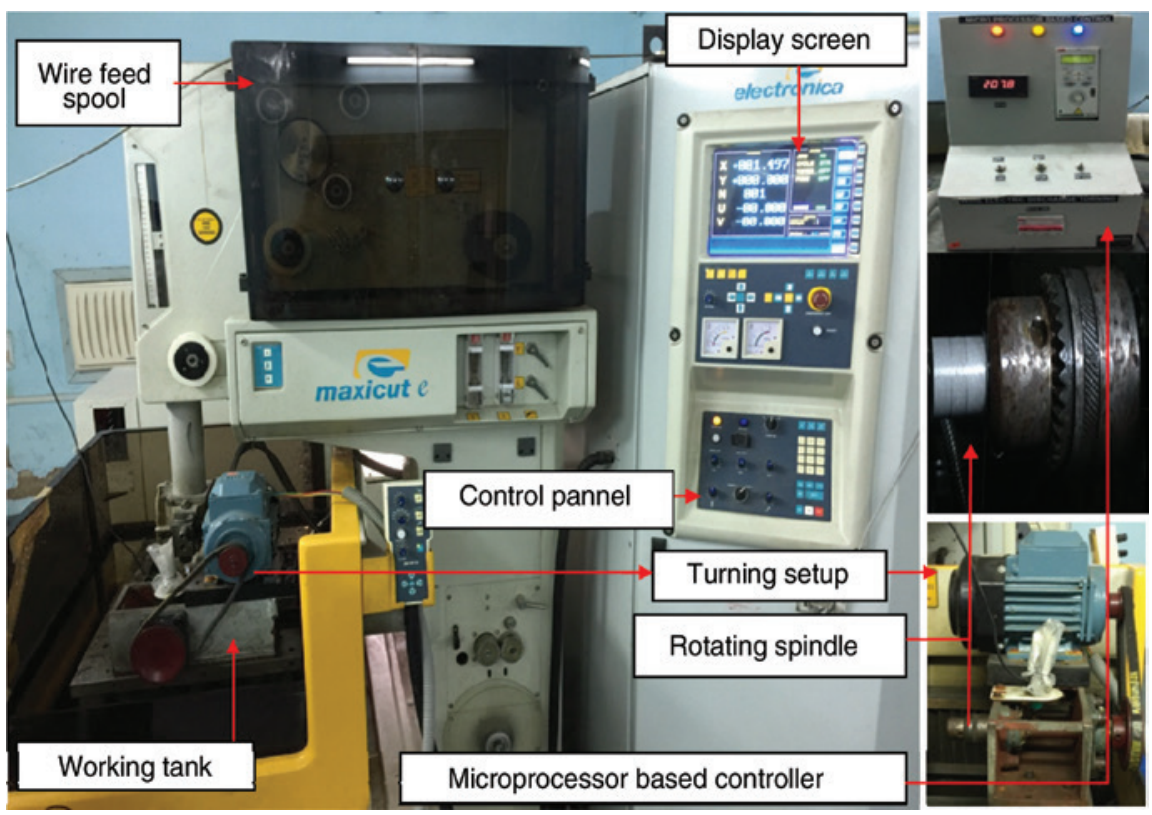

Figure 2: Setup of WED turning experiment. 
and also to observe their effect on MRR and surface roughness. They implemented grey relational analysis for the optimization of the output obtained by ANOVA and concluded that the proposed methodology could effectively deal with the multiresponse optimization problem. Giridharan and Samuel [24] worked on the multiobjective optimization of MRR and surface roughness in WEDT. The WEDT process was modeled using an artificial neural network with the feedforward backpropagation algorithm and using an adaptive neuro-fuzzy inference system. The experiments were designed based on the Taguchi design of experiments to train the neural network and to test its performance. Janardhan and Samuel [25] used pulse train data analysis to investigate the effect of the machining parameters on the performance of WEDT. Thy observed that the rotation of workpiece caused arc regions during WEDT. Ramamurthy et al. [26] compared the surface finish and kerf width produced while machining Ti6Al4V using different wire electrodes. They used the Taguchi L9 array in their study, and concluded that the pulse off-time had a very significant influence on the machining responses. It is thus evident from the literature review that most of the research work was focused on the effect of the process parameters on surface roughness and MRR while machining homogeneous, hard materials.

In this article, we discuss the evaluation of the turning operation on a newly developed hybrid MMC $\mathrm{A} 359 / \mathrm{B}_{4} \mathrm{C} / \mathrm{Al}_{2} \mathrm{O}_{3}[27,28]$. The integrity of the surface created during WEDT is analyzed through different measurement techniques. The effect of rotational speed on the surface roughness and MRR is also examined. The quality of the turned surface is examined by a laser confocal microscope and by field-effect scanning electron microscopy (FE-SEM). The parameters of roughness such as $R a, R q$, and $R z$ are measured using an optical profilometer. The study of recast layers, microhardness depth profiles, and residual stresses in the subsurface is also carried out.

\section{Experimental procedure}

The experimental material consists of the A359 aluminum alloy (Si 8.5-9.5\%, Cu 0.2\%, Mg 0.5-0.7\%, Mn 0.1\%, Fe $0.2 \%$, $\mathrm{Zn} 0.1 \%$, Ti $0.2 \%$, and $\mathrm{Al}$ the remaining) as a base metal and $\mathrm{B}_{4} \mathrm{C}$ and $\mathrm{Al}_{2} \mathrm{O}_{3}$ as reinforcing materials. $\mathrm{A} 359$ has good casting and wettability properties. Its thermophysical properties are shown in Table 1.

$\mathrm{B}_{4} \mathrm{C}$ is the third hardest material after diamond. It is cubic boron nitrate and possesses relatively low specific gravity, high wear resistance, and high impact resistance. $\mathrm{Al}_{2} \mathrm{O}_{3}$ is a hard material and is resistant to wear. It has good dielectric properties, high strength, and good thermal conductivity. The properties of $\mathrm{B}_{4} \mathrm{C}$ and $\mathrm{Al}_{2} \mathrm{O}_{3}$ are also shown in Table 1. The reinforcements were added in the proportion of $2 \%$ by weight of each component to the base metal. Electromagnetic stir-casting process was used in the fabrication process of the hybrid MMC. A detailed description of the working principle and fabrication process has been given in our previous work [29].

The machining work was carried out on a Maxicut $e$ CNC wire-cut electric discharge machine manufactured by Electronica Machine Tool Ltd. A special turning setup was developed and mounted on the conventional WEDM machine (Figure 2) to provide an additional degree of freedom in the rotational axis. A chuck was fitted to a fixture and operated with the help of an electric motor and belt pulley arrangement to rotate workpiece against the traverse motion of the wire electrode. The rotational speed of the motor and chuck could be adjusted using regulators. The traverse motion of the wire electrode in the $X$ - and $Y$-direction of the WEDM machine could be varied to get the desired cylindrical shape of the workpiece. The

Table 2: Technical specifications of the WEDT setup.

\begin{tabular}{ll}
\hline Elements & Specifications and range \\
\hline Working range $(X, Y$, and $Z)(\mathrm{mm})$ & 400,300, and 225 \\
Maximum work table $(w \times d)$ range $(\mathrm{mm})$ & $110 \times 350$ \\
Pulse ON-time $(\mu \mathrm{s})$ & $0.95-1.35$ \\
Pulse OFF time $(\mu \mathrm{s})$ & $120-190$ \\
Turning speed $(\mathrm{rpm})$ & $70-700$ \\
Table feed rate $(\mathrm{mm} / \mathrm{min})$ & 170 \\
Wire feed rate $(\mathrm{mm} / \mathrm{min})$ & $0-10$ \\
Maximum wire tension $(\mathrm{kgf})$ & 1.5 \\
Maximum taper cutting $(\% / \mathrm{mm})$ & $\pm 15 / 100$ \\
\hline
\end{tabular}

Table 3: Technical conditions of WEDT.

\begin{tabular}{ll}
\hline Parameter & Value \\
\hline Duty cycle & 0.55 \\
Gap voltage $(\mathrm{V})$ & 50 \\
Number of rotations $(\mathrm{rpm})$ & $200,400,600$ \\
Workpiece diameter $(\mathrm{mm})$ & 20 \\
Length of turning $(\mathrm{mm})$ & 5 \\
Depth of cut $(\mathrm{mm})$ & 2 \\
Wire diameter $(\mathrm{mm})$ & 0.25 \\
Wire material & Zinc-coated brass \\
Wire feed (m/min) & 1 \\
Wire tension (kgf) & 600 \\
Deionized water conductivity (S) & 13 \\
Flow top (lpm) & 6 \\
Flow bottom (lpm) & 6 \\
\hline
\end{tabular}




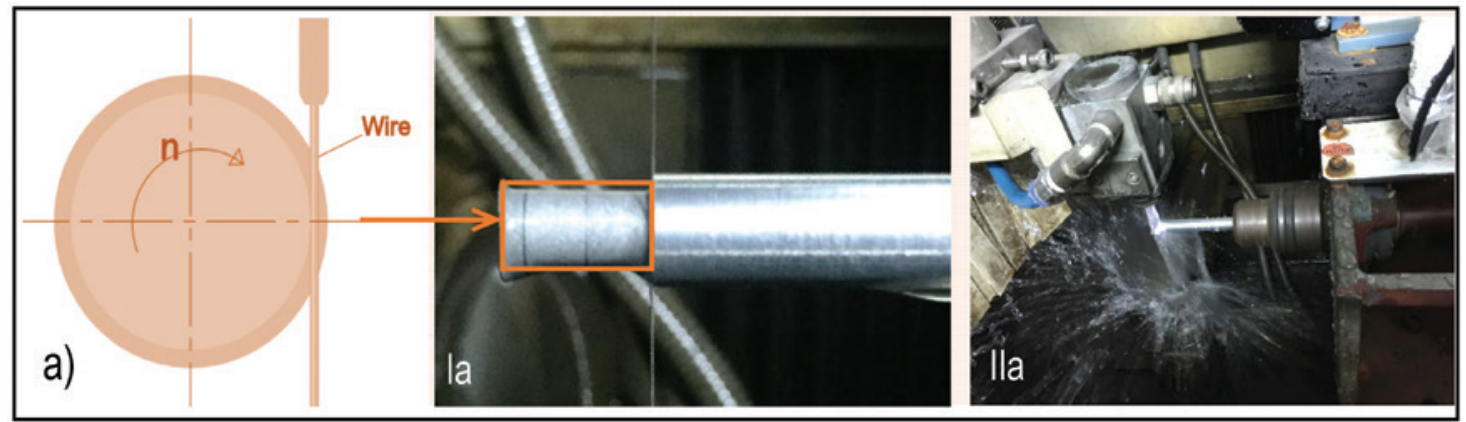

Figure 3: Turning mechanism and turning operation performed on hybrid MMC.

working range and other specifications of the machines are given in Table 2. In the experiment, the turning operation is performed on the developed hybrid MMC. Hence to measure the effect of rotation during WEDT on the tested hybrid MMC, the rotational speed was selected as the variable parameter. The other technical parameters were kept constant, as shown in Table 3. A cylindrical workpiece of diameter $20 \mathrm{~mm}$ was used as the workpiece. The range of the turning speed coul be varied from 70 to $700 \mathrm{rpm}$ using this setup. On the basis of a pilot run, it was concluded that small variations in the rotational speed have only an insignificant effect on the surface quality. Hence to cover the wide range of roational speed, 200, 400, and $600 \mathrm{rpm}$ were selected to create three different surfaces. The turning mechanism and turning operation are shown in Figure 3. The effect of the rotational speed on the resulting surface roughness and MRR was assessed. The surface roughness [Ra: average roughness; $R q$ : average rootmean-square (RMS) roughness; $R z$ : average maximum height of the profile] was measured by a noncontact type roughness tester (MicroProf FRT optical profilometer). All measuring surfaces were scanned, and the scanned data were used to generate the values and graphs using the scanning probe image processor (SPIP) software. Surface roughness values and graphs, along with 3D plot, were also recorded and captured simultaneously. The 3D plot of the surface was done by an in-built sensor (SEN 00003). The other basic measuring parameters of optical profilometer are shown in Table 4.

Table 4: Roughness measurement parameters.

\begin{tabular}{lr}
\hline Parameters & Value \\
\hline Noise filter cut-off, $\lambda s(\mu \mathrm{m})$ & 8 \\
Cut-off wavelength, $\lambda c(\mathrm{~mm})$ & 2.5 \\
Number of cut-offs $(-)$ & 2 \\
Sampling length, $\operatorname{lr}(\mathrm{mm})$ & 2.5 \\
Evaluation length, $\ln (\mathrm{mm})$ & 5 \\
\hline
\end{tabular}

The MRR was also calculated by using Eq. (1) to measure the machining outcomes. In the equation, $D(\mathrm{~mm})$ is the initial workpiece diameter, $d(\mathrm{~mm})$ is the final diameter, $l(\mathrm{~mm})$ is the length of turning, and $t(\mathrm{~min})$ is the machining time.

$$
\mathrm{MRR}=\frac{\pi \times\left(D^{2}-d^{2}\right) \times l}{4 \times t} \mathrm{~mm}^{3} / \mathrm{min} .
$$

The 2D and 3D topographical details of the machined surfaces and their qualitative description were captured by an Olympus Lext OLS 3100 laser confocal microscope. FE-SEM images were also acquired using a Zeiss Supra 55 FE-SEM machine to study the morphological details of the developed MMC and the machined surfaces. While analyzing the subsurface, the residual stress was measured by a GIXRD X-ray diffraction machine. When X-rays are allowed to interact with the sample surface, it produces a diffracted beam which follows Bragg's law $n \lambda=2 d \sin \theta$, where $\lambda$ is the wavelength, $\theta$ is the diffraction angle, and $d$ is the lattice spacing (called the $d$-spacing). The mathematical relation of $d$ vs. $\sin ^{2} \alpha$ (obtained from XRD machine) is then used to calculate the residual strain $\varepsilon$. The residual stresses are measured using Hook's law by taking Young's modulus as $113 \mathrm{GPa}$ and Poison's ratio as 0.275 , as reported by the tensile testing of the developed hybrid MMC. The depth profile of the sample was obtained by polishing and etching ultrathin surface layers down to $\sim 250 \mu \mathrm{m}$. The sample for microhardness testing was prepared by metallographic polishing, and the Vickers indentation test was performed at a load of $100 \mathrm{~g}$ for $10 \mathrm{~s}$. The depth from the surface was taken as the same as in the residual stresses profile.

\section{Results and discussion}

The hybrid MMC of $\mathrm{A} 359+2 \% \mathrm{Al}_{2} \mathrm{O}_{3}+2 \% \mathrm{~B}_{4} \mathrm{C}$ was successfully developed by electromagnetic stir-casting in 
Table 5: Basic physical and mechanical properties of the tested hybrid MMC.

\begin{tabular}{|c|c|c|c|c|c|}
\hline Composite & $\begin{array}{r}\text { Density of the } \\
\text { composite }\left(\mathrm{gm} / \mathrm{cm}^{3}\right)\end{array}$ & $\begin{array}{l}\text { Strength of the } \\
\text { composite (MPa) }\end{array}$ & $\begin{array}{l}\text { Hardness of the } \\
\text { composite (HRC) }\end{array}$ & $\begin{array}{l}\text { Thermal conductivity of } \\
\text { the composite (W/m K) }\end{array}$ & $\begin{array}{l}\text { Toughness of the } \\
\text { composite }\left(\mathrm{J} / \mathrm{m}^{2}\right)\end{array}$ \\
\hline $\mathrm{A} 359+2 \% \mathrm{Al}_{2} \mathrm{O}_{3}+2 \% \mathrm{~B}_{4} \mathrm{C}$ & 2.723 & 119.2 & 54.4 & 136 & 10.1 \\
\hline
\end{tabular}

the laboratory. After testing and characterization, the mechanical properties of the hybrid MMC [25] were measured, which and reported in Table 5.

The FE-SEM images of the developed hybrid MMC are shown in Figure 4A-F. These figures show the mixing of the reinforcement as well as the casting defects. The solid solution of the base aluminum alloy and an interdendritic network of aluminum-boron or aluminum-silicon eutectic mixture can also be observed. Because of the low density of $\mathrm{B}_{4} \mathrm{C}$ particles compared to that of the base metal A359, it flows in the aluminum melt, which causes a nonuniform distribution of these particles. Some regions of the MMC show particle-free zones. However, clustering of the reinforcements are seen at some places, which is due to the lack of turbulence during mixing. A higher magnification image shows the presence of different particles dispersed in the matrix phase, which can be seen as different shades of gray in the images. Some brightly colored phases are also found, which show that there are some particles that reflect the field-emission electrons at a higher rate. These particles may be due to the presence of reinforcements or some other particles of the base metal. However, porosity, microcracks, and small-scale blow-holes are also seen in the composite, but they are

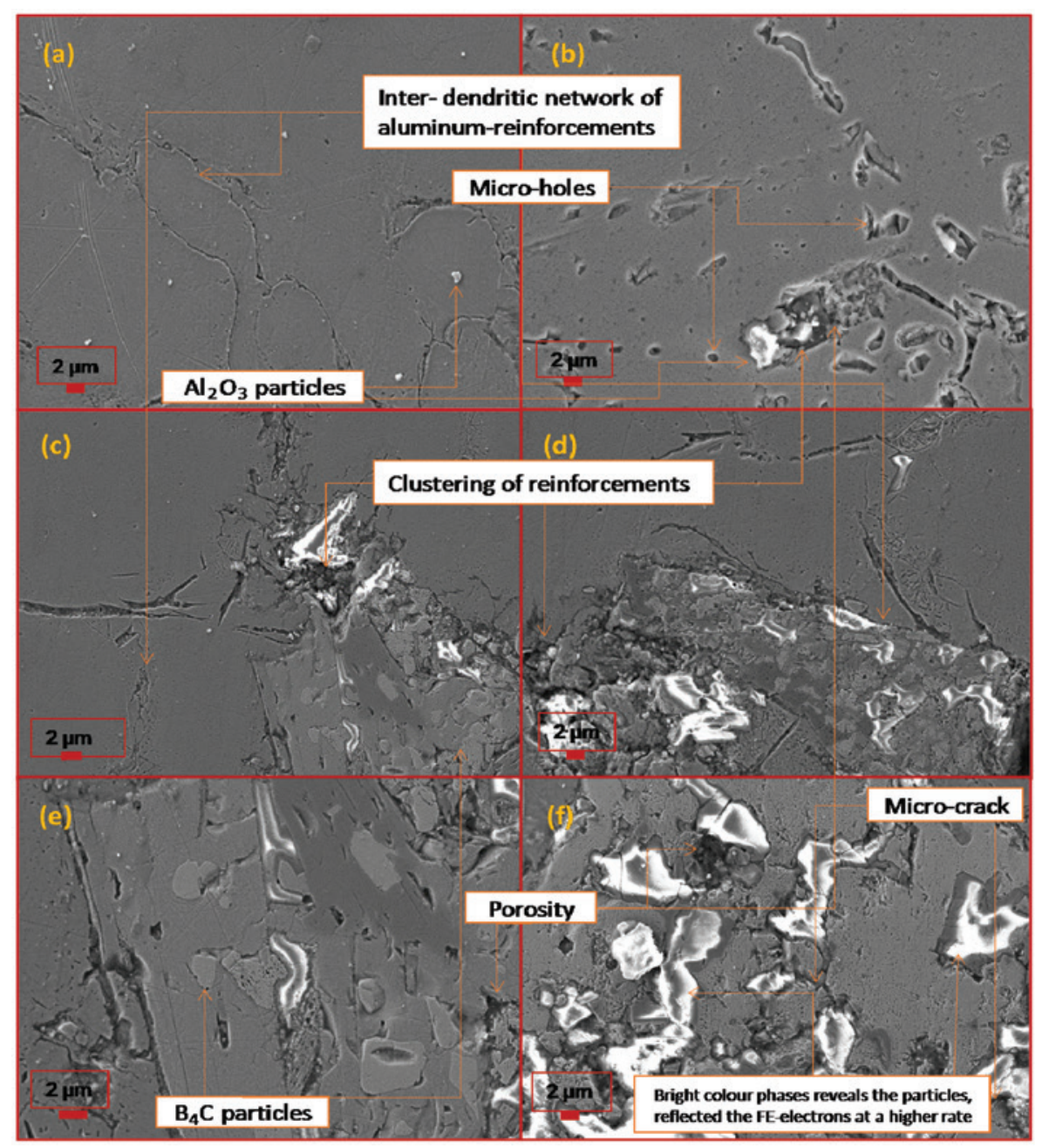

Figure 4: (A-F) FE-SEM images of developed hybrid $M M C A 359 / B_{4} C / A_{2} O_{3}$. 


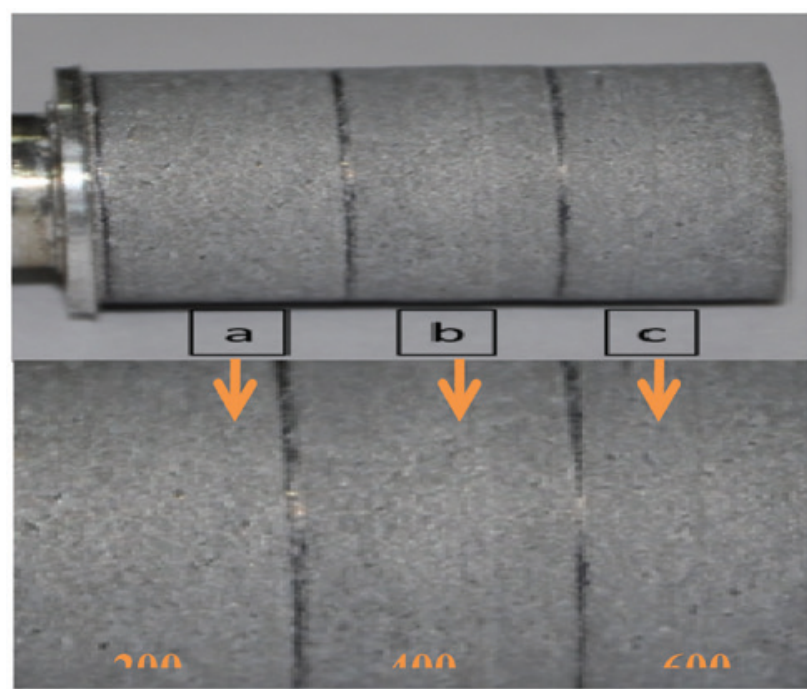

Figure 5: Wire EDM-turned sample.

negligible compared to the better and improved properties of the composite.

Figure 5 shows the hybrid MMC sample turned via WEDT. On visual observation, the surface appeared relatively homogenous without any cutting lines, tool marks, or specific texture or pattern.

The surfaces were not glossy because of the thermal decomposition. On increasing the rotational speed, the surface seemed to improve and more precisely finished. However, small pores became visible on the surface. This is attributed to the melting of the matrix material and simultaneous dielectric flushing, due to which the reinforcements get dislodged from their place and create a void on the surface of the workpiece. It leads to an increase in the surface roughness. The size of these pores was measured to be in the range 5-15 $\mu \mathrm{m}$. It was observed that on increasing of rotational speed from 200 to $600 \mathrm{rpm}$, the average roughness $R a$ changed from 4.8 to $6.2 \mu \mathrm{m}, R q$ from 6.25 to $7.79 \mu \mathrm{m}$, and $R z$ from 38.5 to $45.92 \mu \mathrm{m}$; the corresponding values are shown in Figure 6A-C, respectively.

It is attributed to the fact that, in case of WEDT, the flushing pressure of the deionized water helps to remove the debris and excess material. However, because of the rapid cooling, the solidification rate is nonuniform, which leads to a slightly higher range of the surface roughness value. It was also observed that while increasing the rotational speed, the surface finish showed an improving trend. This is because at higher rotational speeds, the circumferential length of the workpiece crossing the spark zone increases per unit time but the pulse energy (during pulse ON-time) available remains same for the same time interval. So, the spark zone formation decreases, which reduces the rough cutting. Figure $6 \mathrm{~A}$ shows that
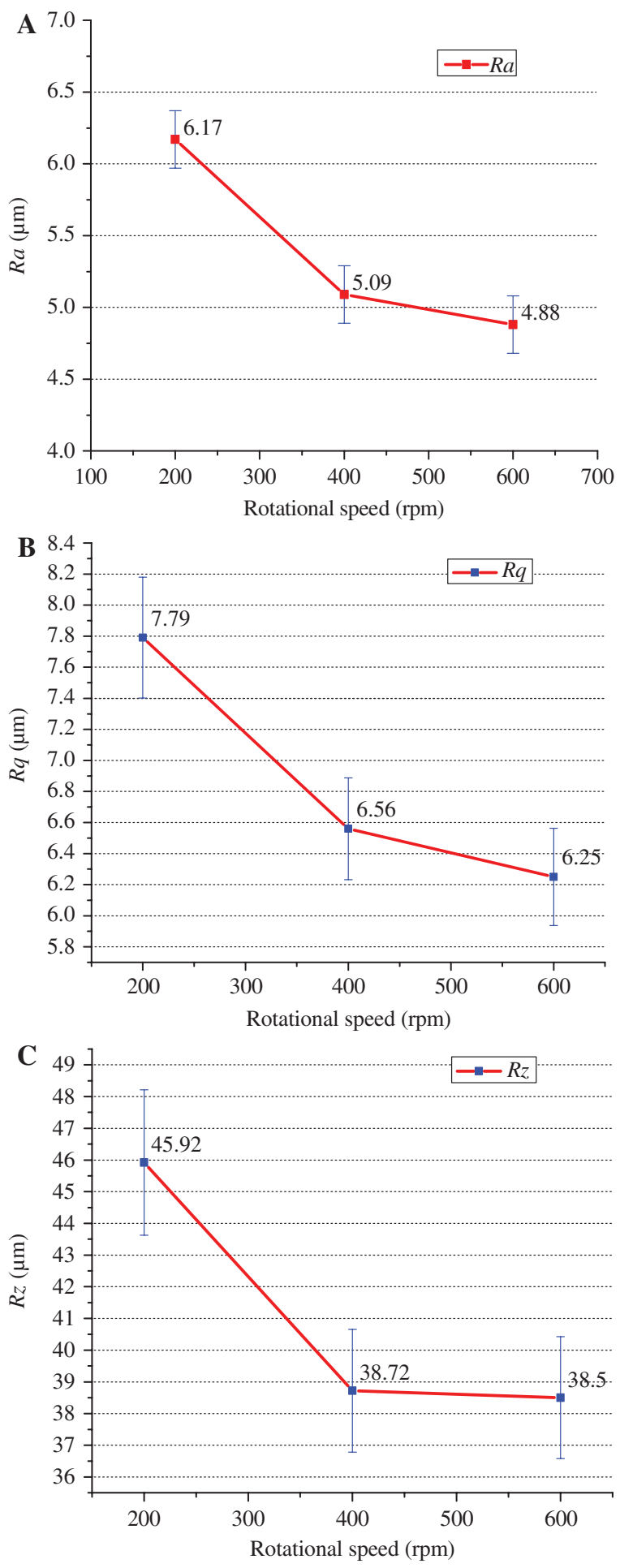

Figure 6: (A) Surface roughness ( $R a) \mathrm{V} / \mathrm{S} \mathrm{rpm}$; (B) surface roughness $(R q) \mathrm{V} / \mathrm{S} \mathrm{rpm}$; and $(\mathrm{C})$ surface roughness $(R z) \mathrm{V} / \mathrm{S} \mathrm{rpm}$.

the surface roughness $R a$ decreases by $22.58 \%$ with the increase in rotational speed. Similar trends are observed for the other roughness parameters ( $R q$ and $R z$ ), which decreases by $19.76 \%$ and $16.16 \%$, respectively. On the other hand, for these reasons, the value of MRR decreased by 


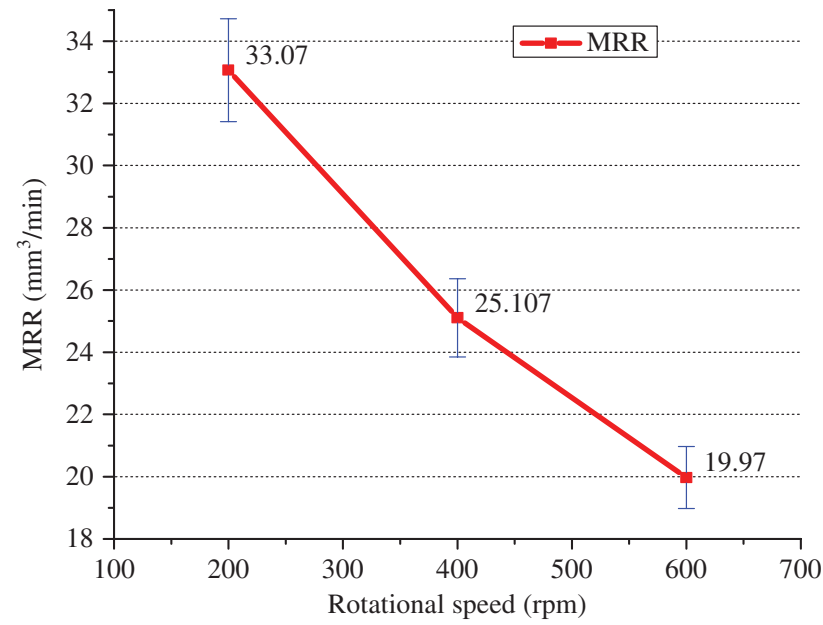

Figure 7: MRR vs. rotation speed.

$39.61 \%$ on increasing the rotational speed up to $600 \mathrm{rpm}$, as shown in Figure 7. In the range of MRR from 32.5 to $19.5 \mathrm{~mm}^{3} / \mathrm{min}$, slow material removal was observed while increasing the rotational speed. A similar trend was also reported by other authors $[10,30,31]$. This is due to the fact that the machine itself adjusts the traverse speed in the range $0.1-0.3 \mathrm{~mm} / \mathrm{min}$. The major difference observed between the cutting and turning operations by the wire EDM process is in the generation of the effective spark. The amount of effective spark produced is less in WEDT than in WEDC for the same time interval and for the same travel length per unit time.

The 2D and 3D visualization of the machined surface at different rotational speeds are shown in Figure 8A-C. It is seen from the 3D images that a circular curvature without any undulation is present on all surfaces. Smallscale porosity as well as voids are observed on the surfaces, which follow a decreasing trend at higher rotational speeds.

Roughness measurement result already indicated that, at lower rotational speeds, the surface roughness increases. At the lower speed, the discharge energy per unit time per unit length is more, which causes a high rate of melting and vaporizing of the workpiece surface, and vice versa. The other reason behind the higher surface roughness is the formation of voids. The reinforcement particles, which were hard to cut and came in the path of the wire electrode, got dislodged from their places and created voids on the surface of the workpiece due to the melting and flushing action of the dielectric fluid. Reinforcement percentage is another important factor affecting these surface defects. The melting of the matrix metal is also obstructed by the clustering of the hard reinforcement particles in the MMC. As a result, they are split in the form of brittle fracture and create voids at that place. The 2D and 3D surface topographical images of the machined surfaces captured using an Olympus Lext OLS 3100 laser confocal microscope at the different rotational speeds are shown in Figure 9A-C. The images show the uneven melting of the surface due to the thermal erosion phenomenon. The workpiece material melts and resolidifies during the process, and this results in the generation of craters, peaks, and valleys over the entire machined surface. It is to be noted that in the no-spark zone, the solidification of the recast layer is nonuniform, which also creates several peaks and valleys. These valleys and craters are mainly responsible for the roughness of the material. Small microcracks are also be observed on uneven surfaces because of the nonuniform cooling of the surface. Moreover, some of the wire material also gets deposited on the machined surface.

The FE-SEM images of the surface show the melting and vaporization of machined surface, deterioration of surface, as well as surface defects such as craters, microcracks, and cavities (Figure 10). Some spherical nodules (droplets) of the resolidified metals are observed on the machined surface. It is due to the nonuniform solidification, i.e. the molten metal does not form a homogeneous phase and appears separately in the form of nodules because of surface tension [32]. The top surface due to the resolidification of the metal is called a recast layer (Figure 11). This layer is formed as a result of the resolidification of the workpiece material as well as decomposition of the wire material (zinc and brass), which get neither vaporized nor flushed out by the deionized flush pressure. Microcracks and a small amount of porosity are also seen in the recast layers, which may be due to the high surface residual stresses during quenching or resolidification of the molten material. These defects lead to the reduced hardening of the top of the machined layer. It was seen from the analysis that at lower rotational speeds, the presence of microcracks and craters on the surface was higher. This is due to the high pulse energy per unit length of the workpiece, which causes more melting from the surface and leads to deep craters and severe microcracks, vaporization, and resolidification.

Because of the thermal erosion of material from the machined surface, an HAZ is formed. This changes the property of machined surface as well as the subsurfaces [10]. Initially, without machining, the residual stress is nonsignificant or negligible but compressive in nature due to the natural solidification and shrinkage of the cast hybrid MMC before turning [27]. It is seen from the graphs (Figure 12) that residual tensile stresses are found in the case of WEDT because of the thermal erosion process. This 
A

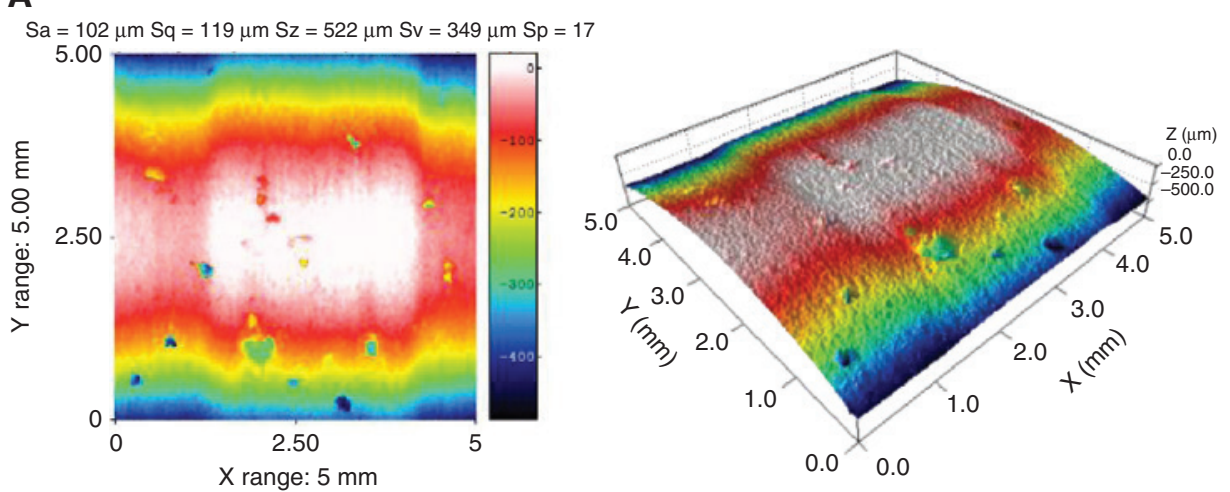

B

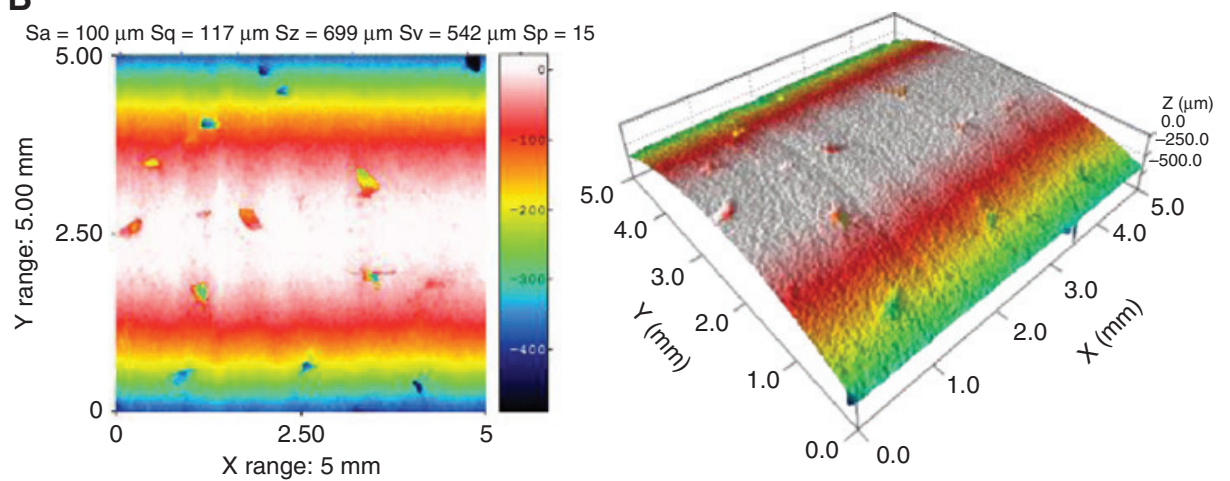

C

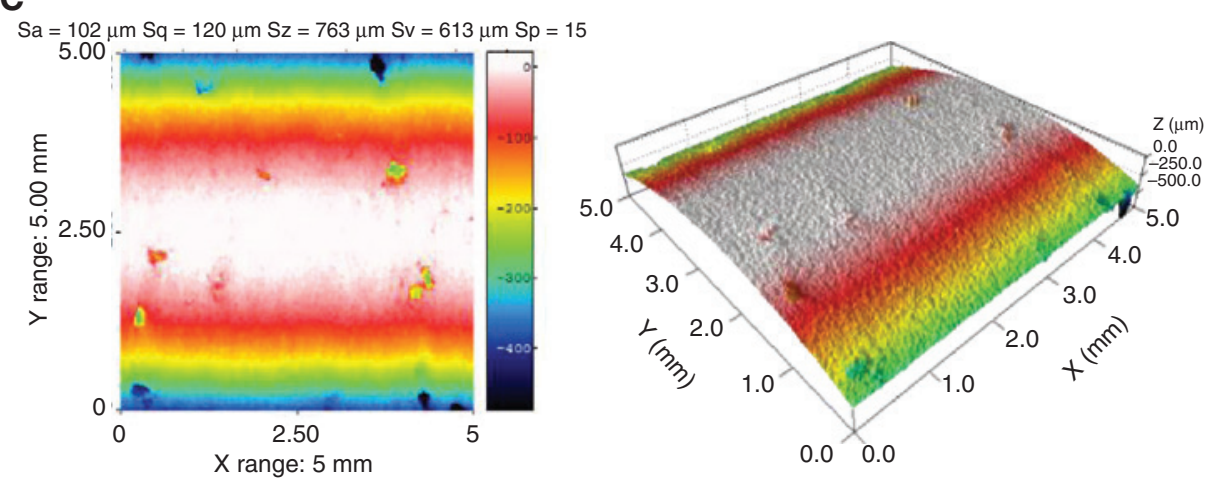

Figure 8: Visualization of the machined surfaces at (A) $200 \mathrm{rpm}$, (B) $400 \mathrm{rpm}$, and (C) $600 \mathrm{rpm}$ (MicroProf FRT optical profilometer).

is attributed to the fact that thermal stresses are induced in the HAZ below the machined surface. Figure 12 shows the variation of the residual stress through the depth from the surface of the machined sample by varying the rotational speed. The residual tensile stress at a depth of $20 \mu \mathrm{m}$ was found to be 340,324 , and $310 \mathrm{MPa}$ for the different rotational speeds, respectively. However, with increasing depth from the surface toward the core of the workpiece, the effect of thermal erosion process is negligible. It reaches the original residual stress of the cast hybrid MMC before turning and is found near the depth of $250 \mu \mathrm{m}$ approximately, which is compressive in nature. Other researchers have also reported the generation of residual tensile stresses in the subsurface [10, 33]. The graph also indicates the decreasing trend of the residual tensile stresses with increasing rotational speeds. It is because at lower rotational speeds, the maximum discharge energy per unit circumferential area per unit time is available. It has more time for melting, vaporizing, quenching, and resolidification for a particular area and hence tends to increase the HAZ and thermal stresses. The other phenomena, such as decomposition and resolidification of workpiece and wire electrode material at the machined surface, are probably responsible for the increase in the residual stress. The results of the microhardness testing are shown in Figure 13. 


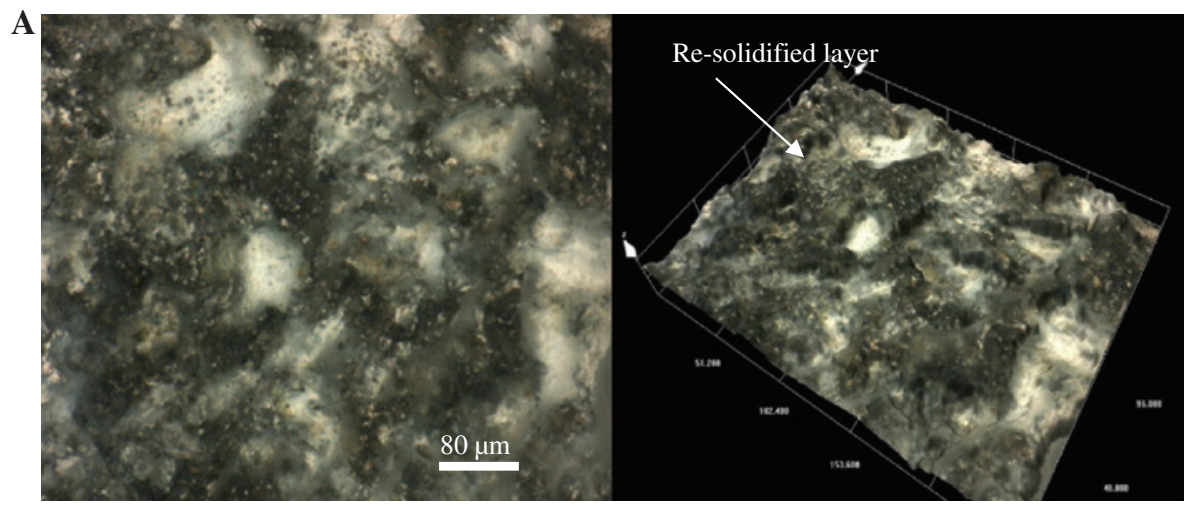

$\mathbf{B}$

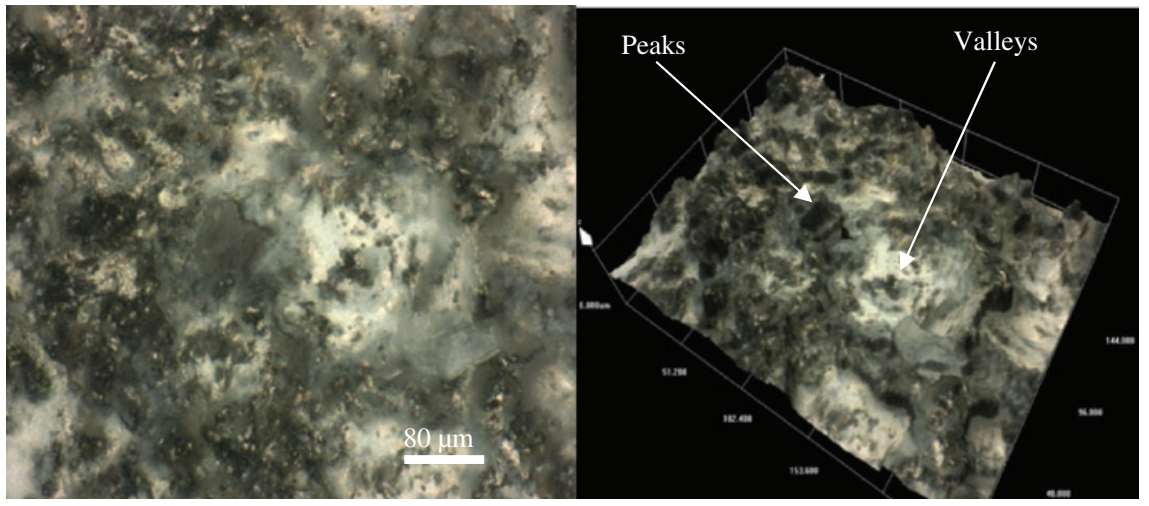

C

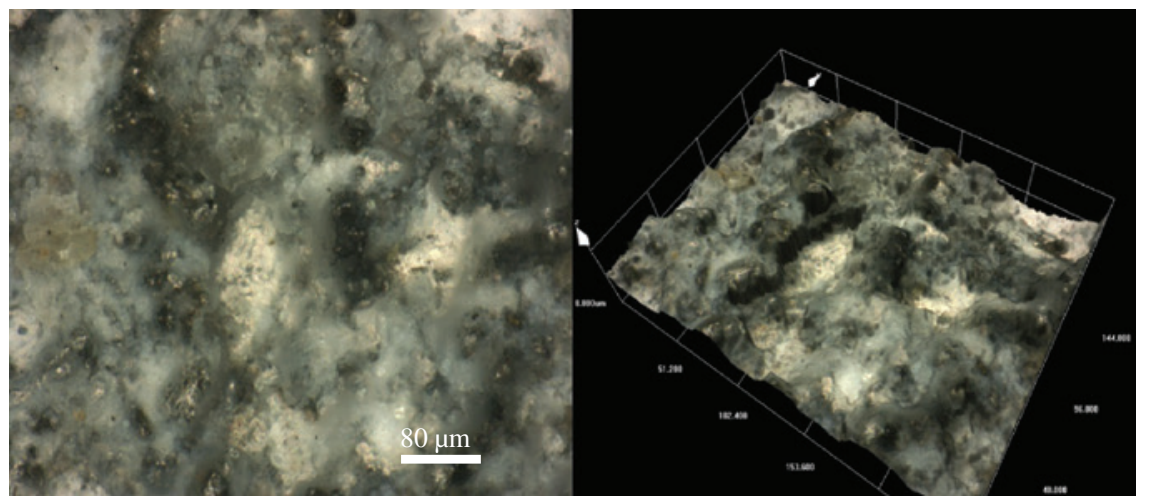

Figure 9: 2D and 3D surface topography of the machined surfaces at (A) $200 \mathrm{rpm},(B) 400 \mathrm{rpm}$, and (C) $600 \mathrm{rpm}$.

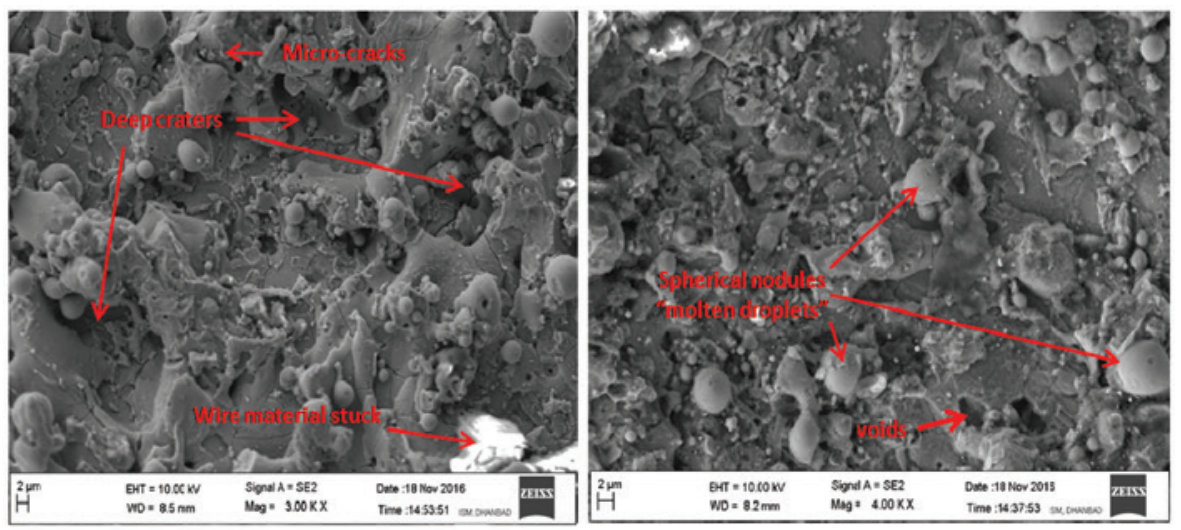

Figure 10: FE-SEM images of the machined surface. 

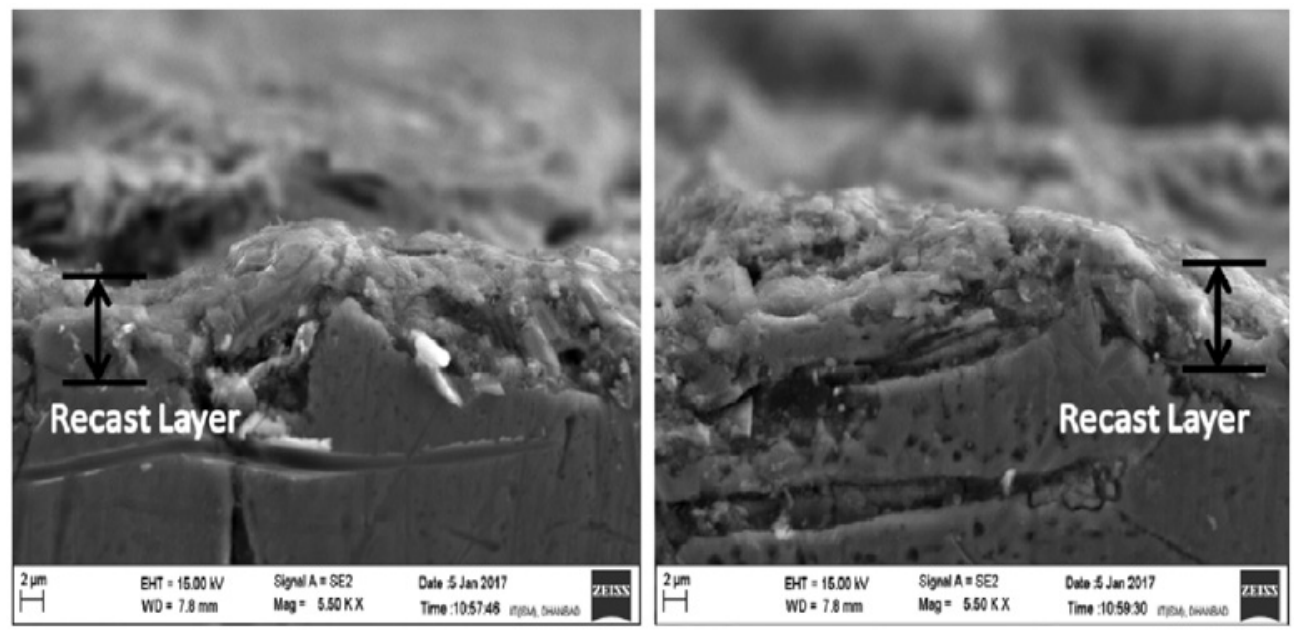

Figure 11: Recast top layer created during WED turning of MMCs.

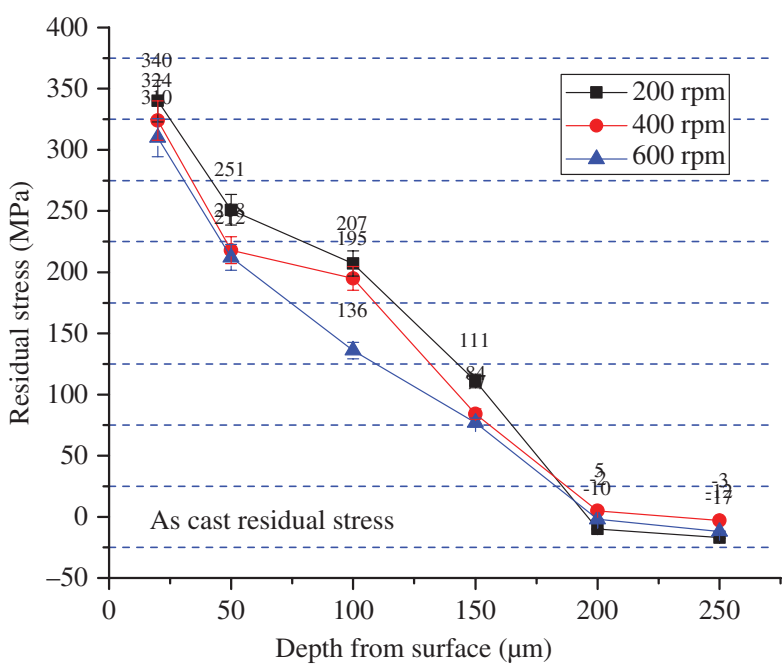

Figure 12: Residual stress vs. depth of penetration.

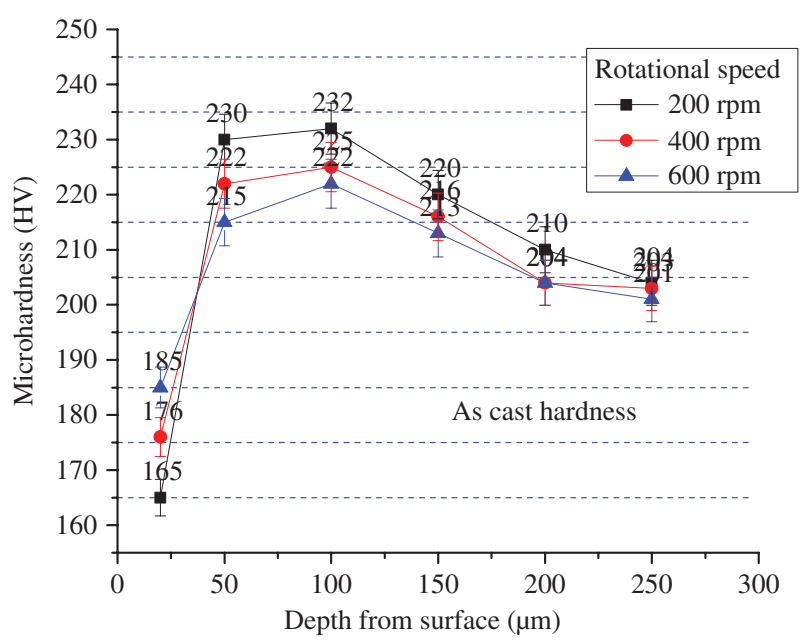

Figure 13: Microhardness vs. depth of penetration.
Initially, the microhardness of the sample was $200 \mathrm{HV}$ before machining. Microhardness was measured along the cross-sectional plane at the initial indentation depth of $20 \mu \mathrm{m}$. It is observed from the graph that, for the WEDT, the microhardness values at a depth of $20 \mu \mathrm{m}$ are found to be 165,176 , and $185 \mathrm{HV}$ at 200, 400, and $600 \mathrm{rpm}$, respectively. These values seem lower than the hardness value of the as-cast hybrid MMC. It is attributed to the reduced hardness of the recast layer. The porosity and micro-holes in the recast layer are high at high discharge energy, which tend to reduce the hardness [10]. Another reason is the oxidation of elements of the recast layers, such as zinc, copper, and brass, which decreases its hardness [33-35]. When the rotational speed increases, the availability of the discharge energy per unit circumferential length of the workpiece decreases. It reduces the thickness of the recast layer, and hence the microhardness shows an increasing trend. As the depth increases beyond the recast layer, the microhardness of the machined surface increases by $\sim 10-15 \%$ up to the depth of $50 \mu \mathrm{m}$. This is due to the microstructural changes of the machined surface during the erosion process. However, these increments become negligible at a depth of $250 \mu \mathrm{m}$.

\section{Conclusion}

The turning operation of the hybrid $\mathrm{MMC} \mathrm{A} 359 / \mathrm{B}_{4} \mathrm{C} / \mathrm{Al}_{2} \mathrm{O}_{3}$ was succesfully performed by WEDT. It can be concluded from the results that WEDT is suitable for hard-to-cut conductive materials such as MMCs. On the basis of surface topography results, it could be concluded that the WEDT surface has a dull appearance because of the deposition of the resolidified layer, which is thermally affected, but 
the surface is free from any particular surface texture or cutting marks. However, a few surface defects like porosity were observed on the machined surface, which were associated with the dislodging of reinforcements from the workpiece surface due to high flushing and circumerencial matrix material melting during the turing operation. The surface roughness values were in the range 4.8-6.2, which shows a decreasing trend with increasing rotational speed. The MRR value decreases on increasing the rotational speed. The major difference observed between cutting and turning by the wire EDM process is in the generation of the effective spark. The amount of effective spark produced is less in WEDT than in WEDC for the same time interval and for the same travel length per unit time. The surface topographical images also revealed that all the machined surfaces had small craters, valleys, and peaks. Overall, the desired surface finish was found with fewer machining defects. Some microcracks were also noticeable on the surface. A recast layer comprising resolidification of the work material and the wire material was also observed on the machined surface. The HAZ in the machined sample was found down to $250 \mu \mathrm{m}$ from the machined surface, which tended to induce residual stresses and an increase in the microhardness of the machined sample.

Acknowledgments: This work was supported by the Indian Institute of Technology (ISM), Dhanbad, India, as well as the project of the Institute of Clean Technologies for Mining and the Utilization of Raw Materials for Energy Use - Sustainability program, No. L01406, financed by the Ministry of Education, Youth and Sports of the Czech Republic, and with support for the long-term conceptual development of the research institution RVO 68145535. This work was also supported by the Slovak Research and Development Agency under contract No. APVV-207-12.

\section{References}

[1] Mazahery A, Shabani MO. J. King Saud Univ. Sci. 2013, 25, 41-48.

[2] Hull D, Clyne TW. An Introduction to Composite Materials, 2nd ed., Cambridge University Press: Cambridge, New York, USA, 1996.

[3] Ibrahim IA, Mohamed FA, Lavernia EJ. J. Mater. Sci. 1991, 26, 1137-1156.

[4] Nag A, Srivastava AK, Dixit AR, Chattopadhyaya S, Mandal A, Hlavacek P, Klichova D, Zelenak M, Hloch S. Lect. Notes Mech. Eng. 2018. Available at: https://doi.org/10.1007/978-981-105329-0_36.

[5] Mardi KB, Dixit AR, Srivastava AK, Mallick A, Scucka J, Hlavacek P, Hloch S, Zelenak M. Lect. Notes Mech. Eng. 2018. Available at: https://doi.org/10.1007/978-981-10-5329-0_46.

[6] Srivastava A, Dixit AR, Tiwari S. Int. J. Adv. Res. Innovation 2014, 2, 516-521.
[7] Gopalakannan S, Senthilvelan T. Int. J. Adv. Manuf. Technol. 2013, 67, 485-493.

[8] Srivastava A, Dixit AR, Tiwari S. Int. J. Adv. Res. Innovation 2014, 2, 511-515.

[9] Scott D, Boyina S, Rajurkar KP. Int. J. Prod. Res. 1991, 29, 2189-2207.

[10] Mandal A, Dixit AR, Das AK, Mandal N. Mater. Manuf. Process. 2016, 31, 860-868.

[11] Liao YS, Huang JT, Chen YH. J. Mater. Process. Technol. 2004, $149,165-171$

[12] Srivastava AK, Dixit AR, Tiwari S. Sci. Eng. Compos. Mater. 2016, doi 10.1515/secm-2015-0287.

[13] Krolczyk G, Legutko S, Nieslony P, Gajek M. Teh. Vjesn. Gaz. 2014, 21, 1307-1311.

[14] Boujelbene M, Bayraktar E, Tebni W, Ben Salem S. Arch. Mater. Sci. Eng. 2009, 37, 110-116.

[15] Wang S, Zheng T, Xie M, Chen Y, Zhang J. Sci. Eng. Compos. Mater. 2015, 23, 599-603.

[16] Marcelo Surez1 0, Vazquez J, Reyes-Russi L. Sci. Eng. Compos. Mater. 2009, 14, 267-276.

[17] Masuzawa T, Fujino M, Kobayashi K, Suzuki T. Bull. Jpn. Soc. Precis. Eng. 1986, 20, 117-120.

[18] Haddad MJ, Alihoseini F, Hadi M, Hadad M, Tehrani AF, Mohammadi A. Int. J. Adv. Manuf. Technol. 2010, 46, 1119-1132.

[19] Haddad MJ, Tehrani AF. J. Mater. Process. Technol. 2008, 198, 77-85.

[20] Mohammadi A, Tehrani AF, Emanian E, Karimi D. J. Mater. Process. Technol. 2008, 205, 283-289.

[21] Rajkumar M, Kanthababu M, Gowri S. In Proceedings of 37th Internations MATADOR Conference, 2012, p. 79, Springer, London Heidelberg New York, DOI 10.1007/978-1-4471-4480-9.

[22] Jabbaripour B, Sadeghi MH, Faridvand S, Shabgard MR. Mach. Sci. Technol. 2012, 16, 419-444.

[23] Baki N, Reddy AC, Rao TB. Proceedings of International Conference on Advanced Materials Manufacturing Technology, JNTUH College of Engineering, Hyderabad, India, 2014.

[24] Giridharan A, Samuel GL. Int. J. Manuf. Technol. Manag. 2013, $27,170-185$.

[25] Janardhan V, Samuel GL. Int. J. Mach. Tools Manuf. 2010, 50, 775-788.

[26] Ramamurthy A, Sivaramakrishnan R, Muthuramalingam T, Venugopal S. Mach. Sci. Technol. 2015, 19, 577-592.

[27] Srivastava AK, Nag A, Dixit AR, Tiwari S, Scucka J, Zelenak M, Hloch S, Hlavacek P. J. Manuf. Process. 2017, 28, 11-20.

[28] Nag A, Ščučka J, Hlavacek P, Klichová D, Srivastava AK, Hloch S, Dixit AR, Foldyna J, Zelenak M. Int. J Adv. Manuf. Technol. 2017. Available at: https://doi.org/10.1007/s00170017-1036-0.

[29] Srivastava AK, Dixit AR, Tiwari S. Indian J. Eng. Mater. Sci. 2016 , 23, 171-180.

[30] Pramanik A. Int. J. Mach. Tools Manuf. 2014, 86, 44-61.

[31] Krishnan AS, Samuel GL. Int. J Adv. Manuf. Technol. 2013, 67, 2021-2032.

[32] Sanjeev K, Rupinder S, Singh TP, Sethi BL. J. Mater. Process. Technol. 2009, 209, 3675-3687.

[33] Grzesik W, Rech J, Wanat T. J. Achiev. Mater. Manuf. Eng. 2006, $18,367-370$.

[34] Das AK, Kumar P, Sethi A, Singh PK, Hussain M. J. Brazilian Soc. Mech. Sci. Eng. 2016, 38, 2029-2037.

[35] Rajmohan T, Palanikumar K, Davim JP. J. Mater. Sci. Technol. 2012, 28, 761-768. 